\title{
Whom Should I Talk To? Emerging Adults' Romantic Relationship Work
}

\author{
Jakob F. Jensen \\ East Carolina University \\ Amy J. Rauer \\ University of Tennessee \\ Yuliana Rodriguez \\ East Carolina University \\ Andrew S. Brimhall \\ East Carolina University
}

This exploratory study examined how often young adults discussed their romantic relationship problems with their social networks: partners, friends, mothers, and fathers ("relationship work" or RW). Using a sample of 82 heterosexual, romantically involved young adults, we found that participants engaged in RW most frequently with partners, followed by friends and mothers, and least with fathers. Suggesting that young adults vary in their disclosure patterns, cluster analyses revealed three groups: disclosers, who shared romantic challenges with all parties examined; selectives, who primarily discussed romantic problems with partners and mothers; and discretes, who engaged in low RW overall. Although RW with mothers was not concurrently associated with partners' love and conflict, RW with fathers was associated with less love and greater conflict. Moreover, when looking at a subsample of 56 participants who remained together over the course of a year, greater reported romantic love at Time 1 predicted less RW with fathers 1 year later at Time 2 . Findings suggest that romantic and social dynamics in emerging adulthood may determine the extent to which young adults confide in their mothers and fathers about romantic problems, but that both parents play important roles. Scholars need to consider the influence of the social network, including parents, on romantic relationship functioning, particularly in young adulthood. Practitioners may also benefit from discussing appropriate and helpful ways of actively involving the social network in romantic challenges.

Keywords: disclosure, social networks, romantic relationships, parent-child dynamics

\section{Introduction}

Although nearly 2 decades have passed since social scientists called for researchers to more closely examine everyday interactions between romantic partners and members of their social network (Bradbury, Fincham, \& Beach, 2000), little is still known regarding the nature of what couples discuss with others and how this may shape their romantic relationships. Such a gap in the literature is especially notable considering Huston's (2000) socioecological model, which clearly links 
interactions with members of the couple's social network with romantic functioning. This process, often referred to as relationship work (RW), is defined as the frequency with which an individual discusses their romantic problems with another person (Helms, Crouter, \& McHale, 2003). The purpose of this exploratory study is to examine how an individual's social network (e.g., partners, friends, mothers, fathers) influences the way emerging adults (ages 18 to 29; Arnett, Zukauskiene, \& Sugimura, 2014) engage in RW and how these decisions influence their romantic functioning.

Previous work on RW patterns suggests that across the lifespan, individuals benefit from discussing romantic problems (e.g., enhanced relationship quality), so long as discussions with friends do not supplant discussions with partners (Helms et al., 2003; Jensen \& Rauer, 2015; Proulx, Helms, \& Payne, 2004). The benefits of bringing in others' perspectives for relationship functioning appear particularly pronounced for younger adults (Jensen \& Rauer, 2014), who are learning how to maintain newly developed romantic relationships. Although this small but growing literature highlights the important role of friends in romantic relationships, today's current emerging adult cohort may be more prone to share relationship problems with parents due to increased access to parents via cell phones and social media (Kanter, Afifi, \& Robbins, 2012). Whether involving mothers and fathers yields similar effects on romantic functioning is unclear, as emerging adults must also navigate the developmental task of separating from parents, such as building autonomy and making their own decisions about interpersonal relationships (Erikson, 1968; Pederson, 2017). Furthermore, there may be variability in to whom emerging adults turn when faced with romantic trials, and such differences in choice of confidants (romantic partners, friends, mothers, fathers) may be important in shaping romantic outcomes. Given the importance of romantic relationships for emerging adults' development and adjustment (Rauer, Pettit, Lansford, Bates, \& Dodge, 2013), understanding how the social network supports these relationships is necessary.

\section{Theoretical and Empirical Perspectives on Relationship Work}

Milardo (1982) posited that social networks are especially critical in newly developing romantic relationships, claiming that any romantic union both influences and is influenced by the social context in which it grows. Members of a couple's social circle, including friends and parents, act as sources of influence and provide feedback that shapes couple dynamics (Etcheyerry \& Agnew, 2004). According to Huston's (2000) socioecological model, which suggests that romantic relationships are embedded in social networks, the influence of social network members on romantic functioning should be accounted for.

As to how members of the social network might contribute directly to romantic functioning, Helms and colleagues (2003) examined a novel construct they called "marriage work," operationalized as the disclosure of romantic issues to a spouse or a close friend. Not only did they find that middle-aged wives were more likely than husbands to share marital problems with friends, they found that wives who frequently discussed problems with friends but not with husbands were more likely to report less love and more marital conflict. Regarding RW earlier in the lifespan, young adults who frequently discussed relationship problems with friends but not with partners reported concurrent lower levels of happiness, commitment, and love (Jensen \& Rauer, 2014). This pattern of findings has been replicated across diverse samples (Jensen \& Rauer, 2015; Proulx et al., 2004; Rodriguez, Helms, Supple, \& Hengstebeck, 2016), suggesting that engaging in RW with a partner appears 
beneficial across the lifespan and among various ethnic groups. Relatedly, Ruiz and Stadtlander (2015) examined the links between romantic challenges and social functioning among a group of females whose combat veteran partners were struggling with posttraumatic stress disorder. The authors found that romantic issues were directly associated with social interaction, as the stigma of dealing with posttraumatic stress disorder in their relationship resulted in these women socially withdrawing and depending upon social media for their interaction and support with friends. This act of turning away from the partner and engaging in discussions about romantic challenges with friends online may have been driven by romantic difficulties and exacerbated relationship problems for some females.

Indeed, results from previous studies offer strong support for the importance of RW with a partner, consistent with work documenting the benefits of interpersonal communication for relationship functioning (Lavner, Karney, \& Bradbury, 2016). To note, preference in confidant (e.g., partner, friend, parent) may be influenced by differences in personality or adult attachments (Wei, Russell, \& Zakalik, 2005). Although RW studies also document the potential individual and relational benefits of discussing romantic relationships with friends, existing studies have not accounted for disclosing romantic problems to parents. Such a gap represents a notable limitation when considering the romantic functioning of emerging adults, who today frequently involve their parents in their personal social matters and rely on advice from parents more than previous cohorts (Coomes \& DeBard, 2004; Gentzler, Oberhauser, Westerman, \& Nadorf, 2011). Therefore, when considering how the social network may critically influence romantic functioning, an examination of parents' role in this process appears warranted.

\section{Parental Influences on Emerging Adult Children}

Erikson (1968) noted that both separation from parents and subsequent fusion with a romantic partner are critical developmental tasks for emerging adults. However, today's college students as a cohort have been characterized by their closeness with their parents (Pizzolato \& Hicklen, 2011). High parental involvement via cell phones and social media has contributed to this group being more likely to welcome parental guidance (Kanter et al., 2012). Nevertheless, separation from the parentchild relationship as a result of forming romantic relationships remains a key task during this time. Highlighting the need for such autonomy and separation, one recent study showed that university students reported the highest subjective well-being when students perceived their parents as supportive of their autonomy during college (Ratelle, Simard, \& Guay, 2013). In contrast, feeling controlled by one's parents in young adulthood has been linked to poorer well-being (Schiffrin et al., 2014). Consequently, today's emerging adults are situated in a truly unique social stage, attempting to develop romantic intimacy while separating from the parents to whom they are closer than any previous generation.

As to the importance of parental involvement in emerging adults' romantic relationships, longitudinal work from Sprecher and Felmlee (1992) suggests that parental approval may be just as critical as approval from friends. Individuals reported greater relationship functioning both concurrently and over time the more that they perceived approval from parents and friends. Yet, it is unclear whether emerging adult children would also solicit advice from their parents about romantic challenges. Suggesting that they might, Pizzolato and Hicklen (2011) found that many emerging 
adult children, particularly females, solicit parental help when making important decisions. However, qualitative work from Carlson (2014) suggests emerging adults may differentiate between issues they discuss with parents versus others. For example, advice from parents was more frequently sought regarding work-life balance but less frequently sought regarding social or relational topics. Of the social/relational advice received, friendship advice was almost entirely solicited and romantic relationship or sexuality advice was often unsolicited. On the other hand, parent-child conversations about sex and dating appear to blossom over time as participants described increased openness and comfort in talking about sexual topics with both mothers and fathers from the first to the fourth year of college (Morgan, Thorne, \& Zurbriggen, 2010). Overall, it appears that among emerging adults today, parental advice-giving is common and influential; thus, researchers should examine parental influence on romantic challenges.

\section{Who Turns to Their Parents When Faced With a Romantic Challenge and Why?}

Although some researchers have posited that young adults are more likely to turn to partners over friends (Jensen \& Rauer, 2014), little is known regarding a preference for engaging in RW discussions with mothers or fathers. Emerging adults communicate about their relationships more frequently overall with mothers (Arnold, O'Neal, \& Futris, 2013), and they are more likely to turn to mothers than fathers when seeking advice or encouragement (Markiewicz, Lawford, Doyle, \& Haggart, 2006). As to why, Aldeis and Alfif (2013) found that both male and female college students reported they were more likely to disclose risky behaviors and solicit counsel from mothers than fathers because mothers were more likely to display empathy. Furthermore, because mothers and daughters are taught to foster relationships, the mother-daughter dyad tends to be the most intimate parent-child relationship (Fisher \& Miller-Day, 2006). In contrast, males are more likely than females to turn to fathers (Markiewicz et al., 2006).

Some of the differences in whom individuals turn to when faced with romantic problems may be systematic, given that previous work has identified that some individuals engage in greater RW with both partners and friends, whereas others choose to only disclose to one or the other (Helms et al., 2003; Jensen \& Rauer, 2014). As to the effects of these different disclosure patterns, Helms et al. (2003) found that the wives who were high in RW with a friend but low in RW with their spouse reported less love and more arguing, whereas Jensen and Rauer (2014) found that those who disclosed to both friends and partners reported greater romantic happiness. We extend previous work considering group differences in RW to uncover whether consistent differences emerged between individuals in patterns of RW with partner, friends, and parents.

It also merits consideration that when emerging adults are faced with the choice of multiple confidants, aspects of the romantic relationship (i.e., love, conflict) likely influence with whom they choose to share problems (Smetana, Metzger, Gettman, \& Campione-Barr, 2006). Jensen and Rauer (2015) found that emerging adult females who reported more romantic love also reported more frequent RW with their partners. Conversely, females who reported greater conflict were more likely to decrease RW with partners over time. Relatedly, parental approval of a partner has been linked with romantic stability (Sprecher \& Felmlee, 1992), yet researchers have largely overlooked how romantic relationship quality is linked with decisions to disclose challenges to parents. In light of 
previous work examining links between RW with partners and friends and self-reported love and conflict, it seems logical to examine similar links with parents.

\section{Current Study}

Despite research linking RW and romantic outcomes, social scientists have yet to consider that emerging adults today are attempting to develop romantic intimacy within the context of being more connected to parents than previous generations (Gentzler et al., 2011). The present exploratory study thus sought to examine the role that mothers and fathers play in addition to partners and friends in acting as confidants when emerging adults face romantic challenges. We first considered the frequency of disclosing romantic concerns to partners, friends, mothers, and fathers. Because not all turn to the same individuals when experiencing romantic turmoil, we also investigated whether emerging adults may differ in their preferences for frequency of RW and choice in confidant. Next, correlates of RW with partners and friends (e.g., love, conflict; Helms et al. 2003; Jensen \& Rauer, 2014) were considered as they concurrently relate to RW with parents. Finally, to explore direction of effects, we examined whether early reports of love and conflict predicted later reports of RW with mothers and fathers.

The current study included the following research questions:

Research Question 1: With whom are emerging adults engaging in RW (partners, friends, mothers, fathers)?

Research Question 2: Do individuals differ in their choices of confidants?

Research Question 3: Are romantic love and conflict concurrently associated with RW with partners, friends, mothers, or fathers?

Research Question 4: Are early reports of love and conflict predictive of reports of RW with mothers and fathers 1 year later?

Consistent with previous RW studies revealing that young adults engage in more frequent RW with partners than friends (Jensen \& Rauer, 2015), we hypothesized that individuals would engage in the most RW with their partners, followed by friends, then mothers, then fathers. Next, based upon differences in personality, attachment, topic choice, or other factors (Wei et al., 2005), we hypothesized that group differences in RW would emerge such that some frequently disclose problems to all four parties, others disclose primarily to partners, and a third group discloses infrequently to all. Next, partially based on previous RW studies cited above (e.g., Helms et al., 2003), we predicted greater love and less conflict would be concurrently linked with RW with partners and mothers, whereas less love and greater conflict would be linked with greater RW with friends and fathers. Similarly, given that mothers are more often the primary attachment figure than fathers (Bowlby, 1982), we hypothesized that Time 1 (T1) love would predict greater RW with mothers 1 year later at Time 2 (T2), and T1 conflict should predict greater RW with fathers 1 year later at $\mathrm{T} 2$. 


\section{Method}

\section{Participants and Procedures}

Data in this article were drawn from a 2014 study examining romantic relationships in emerging adulthood (author citation blinded for review) over two time points approximately 1 year apart. Only procedures relevant to the current study are discussed here. Participants were recruited from statistics, social sciences, engineering, and political science courses at a university in the southern part of the United States. A total of 190 young adults completed the questionnaire. The average age of participants was 21.1 years old $(S D=1.5$; range $=19-29)$ with most indicating they were Caucasian (87\%) or African American (9\%). Ninety-four percent of participants had same-sex friends. Participants' average friendship length was 8.9 years $(S D=7.7)$. No participants were married or had children.

In the current study, we focused on two subsamples of the 190 participants. The first subsample, used to answer our first three research questions, was comprised of 82 heterosexual individuals (68 females, 14 males) ranging in age from 19 to 29 years $(M=21.1)$ involved in a romantic relationship at T2. The four RW measures described below (RW with partner, RW with friend, RW with mother, and RW with father) were only captured at T2. Of these 82 participants, average romantic relationship length was 26.5 months $(S D=20.9)$. For longitudinal analyses utilized to answer our fourth research question, we examined a subsample of 56 heterosexual participants ( 46 females, 10 males) ranging in age from 19 to $29(M=21.2)$ who remained in the same relationship from T1 to T2. Average relationship length for these participants was 28.8 months $(S D=21.4)$.

Study procedures included completing a questionnaire assessing personal, social, and romantic variables of interest. Questionnaires were either completed in the on-campus lab or picked up in the lab and mailed to the research team after completion. Participants completed questionnaires in one sitting (15-20 min) and were compensated $\$ 10$ at each time point. Questionnaires were completed at both $\mathrm{T} 1$ and $\mathrm{T} 2$, approximately 1 year apart.

\section{Measures}

\section{Relationship work}

The frequency of engaging in RW with partners, friends, mothers, and fathers was assessed using a modified version of the validated Marriage Work Scale (Helms et al., 2003; Jensen \& Rauer, 2014). This measure assessed the frequency of discussing romantic problems with others on a 9-point scale ranging from 1 (never) to 9 (always), with higher scores indicating more frequent RW. In the current study, we used five items from the original 10-item scale. Items were retained that were relevant to younger couples (i.e., items were dropped that pertained to childrearing and joint household labor). The five items that were retained captured relationship communication, decision making, finances, relations with the partner's family, and social life and leisure (e.g., "How often do you bring up your financial situation?"). Participants were directed to report on romantic relationship "concerns or problems" in each area and how frequently they were discussed with each of the four above-named individuals. Due to limitations of the study design, RW was only examined at T2. The RW scale 
showed acceptable reliability for partners $(\alpha=.75)$, friends $(\alpha=.85)$, mothers $(\alpha=.86)$, and fathers $(\alpha=.90)$.

\section{Romantic love and conflict}

To assess romantic love and conflict, participants completed the 10-item love subscale and the fiveitem conflict subscale from Braiker and Kelley's (1979) Intimate Relations Questionnaire. The love subscale measured the degree to which the individual reported feeling love and belonging (e.g., "To what extent do you love your partner at this stage?" T1, $\mathrm{v}=.83$; T2, $\alpha=.80$ ). The conflict subscale measured the individual's overt behavioral conflict and communication of negative affect with a romantic partner (e.g., "How often do you and your partner argue with one another?" T1, $\alpha=.79$; T2, $\alpha=.73)$. Both subscales were evaluated on a 9 -point scale $(1=$ not at all to $9=$ very much $)$.

\section{Data Analysis}

To identify to whom emerging adults turned when faced with romantic challenges, a one-way analysis of variance (ANOVA) was conducted among the sample of 82 romantically involved young adults at T2 to compare mean differences of RW with partners, friends, mothers, and fathers. To examine clustering of disclosure patterns and potential confidant preference, a combination of both hierarchical and nonhierarchical cluster analyses were conducted per recommendations (Henry, Tolan, \& Gorman-Smith, 2005). The sample size of 82 is sufficient for conducting analyses on the four clustering variables (RW with partner, RW with friend, RW with mother, RW with father), as guidelines suggest having at least 10 cases per clustering dimension or $2 m$ cases, where $m$ equals the number of clustering variables (Mooi \& Sarstedt, 2010). Ward's (1963) minimum variance method was employed to hierarchically identify a potential number of clusters and their initial starting points. Milligan and Cooper's $(1985,1988)$ criteria determined the number of clusters: Sarle's cubic clustering criterion, the pseudo- $F$ statistic, and the pseudo-T2 statistic. Nonhierarchical clustering methods in SPSS Version 21 then utilized the preestablished number of clusters and the hierarchically determined cluster centers to assign observations to the clusters. The $k$-means algorithm was performed to divide the cases into their respective clusters based upon their distance from each cluster mean. Means were recalculated and individual cases were reassigned based upon their distance from the new cluster means. This cycle repeated until cases retained cluster membership (Hair \& Black, 1998).

To next explore concurrent links between RW patterns and love and conflict among the 82 romantically involved young adults at T2, both a path model was fit using Mplus 7 and a series of ANOVAs were conducted in SPSS Version 21. Finally, to determine whether T1 love and conflict predicted later reports of RW with mothers and fathers, a path model was fit which accounted for the autoregressive effects of love and conflict over time. These analyses were conducted only examining the sample of 56 participants who remained in the same relationships from T1 to T2. Given the previous literature examining RW with partners and friends discussed above and to extend the literature, the current study considered more carefully processes associated with RW with parents. Across the path models, missing data were handled using full information maximum likelihood. Goodness of fit was evaluated using the chi-square statistic, comparative fit index, root mean square error of approximation, and standardized root mean square residual (Bentler, 1995; Hu \& Bentler, 1999). All analyses conducted were appropriate based on statistical power allocated by our sample 
size (Steiger, \& Fouladi, 2009). To note, assumptions of parametric analyses were checked, and all were sufficiently met to proceed with inferential statistics.

\section{Results}

Descriptive statistics and intercorrelations for all variables are presented in Table 1. Independent $t$ tests revealed no gender differences on any study variables.

Table 1. Descriptive Statistics and Intercorrelations for Study Variables at Time $2(T 2 ; \mathrm{N}=82)$

\begin{tabular}{lcccccc}
\hline Variables & 1. & 2. & 3. & 4. & 5. & 6. \\
\hline T2 love & - & & & & & \\
T2 conflict & -.14 & - & & & & \\
T2 RW with partners & $.40^{* *}$ & -.07 & - & & & \\
T2 RW with friends & $-.20^{\dagger}$ & .06 & $.33^{* *}$ & - & & \\
T2 RW with mothers & .14 & -.14 & $.40^{* *}$ & $.41^{* *}$ & - & \\
T2 RW with fathers & .13 & -.27 & $.32^{* *}$ & $.35^{* *}$ & $.66^{* *}$ & - \\
$M$ & 7.58 & 3.40 & 7.27 & 5.37 & 5.56 & 4.63 \\
$S D$ & .92 & 1.19 & 1.25 & 1.79 & 1.98 & 2.18 \\
\hline
\end{tabular}

Note. $\mathrm{RW}=$ relationship work.

$\dagger p<.10 .{ }^{* *} p<.01$.

\section{Emerging Adult Patterns of RW With Others: Variable and Person-Centered Approaches}

To answer the first research question examining emerging adults' frequency of RW with confidants, a one-way ANOVA was conducted to determine differences in mean levels of RW with partners, friends, mothers, and fathers. There was a significant effect of confidant on RW at the $p<.01$ level for the four confidants, $F(3,327)=30.75, p=.00$. Tukey's post hoc analyses revealed that emerging adults engaged in significantly more RW with partners $(M=7.27, S D=1.25)$ than with friends $(M=$ 5.37, $S D=1.79)$, with mothers $(M=5.56, S D=1.98)$, and with fathers $(M=4.63, S D=2.18)$.

Furthermore, post hoc analyses revealed that they engaged in significantly more RW with mothers than with fathers. However, emerging adults did not differ in RW done with mothers and friends. Yet, they did engage in significantly more RW with friends than with fathers. Post hoc analyses therefore revealed that participants thus engaged in RW most frequently with partners, followed by friends and mothers, and engaged in the least amount of RW with fathers.

To examine potential variability in RW patterns, cluster analyses revealed three types of emerging adults who differed significantly in their RW behaviors (see Figure 1 and Table 2). Those in the disclosers cluster ( $n=24 ; 29.3 \%)$ were notable in that they engaged in high levels of RW with all four individuals: partners, friends, mothers, and fathers. The disclosers cluster was composed of 21 females (87.5\%) and three males (12.5\%), of whom 22 were Caucasian (91.7\%) and two were Hispanic (8.3\%). Disclosers engaged in more RW with partners, RW with friends, and RW with fathers than 
did selectives and discretes (described below). Disclosers also engaged in more RW with mothers than did discretes. Next, those in the selectives cluster $(n=35 ; 42.7 \%)$ participated in high levels of RW with partners and with mothers, and less RW with friends and fathers. The selectives cluster was composed of 27 females (77.1\%) and eight males (22.9\%) and included 34 Caucasian participants (97.1\%) and one African American (2.9\%). Selectives engaged in RW with partners less than disclosers, but more than discretes. Selectives also engaged in RW with friends less than disclosers. Selectives engaged in equal amounts of RW with mothers as did disclosers and more than discretes. Additionally, selectives engaged in less RW with fathers than disclosers and more than discretes. Finally, those in the discretes cluster $(n=23 ; 28.0 \%)$ engaged in low RW overall and most frequently with only partners. The discretes cluster was comprised of 20 females (87\%) and three males (13\%), and included 20 Caucasian participants (87\%) and three African American participants (13\%). Discretes engaged in less RW with partners, mothers, and fathers than did individuals in the other two clusters. They engaged in equal levels of RW with friends as did discretes.

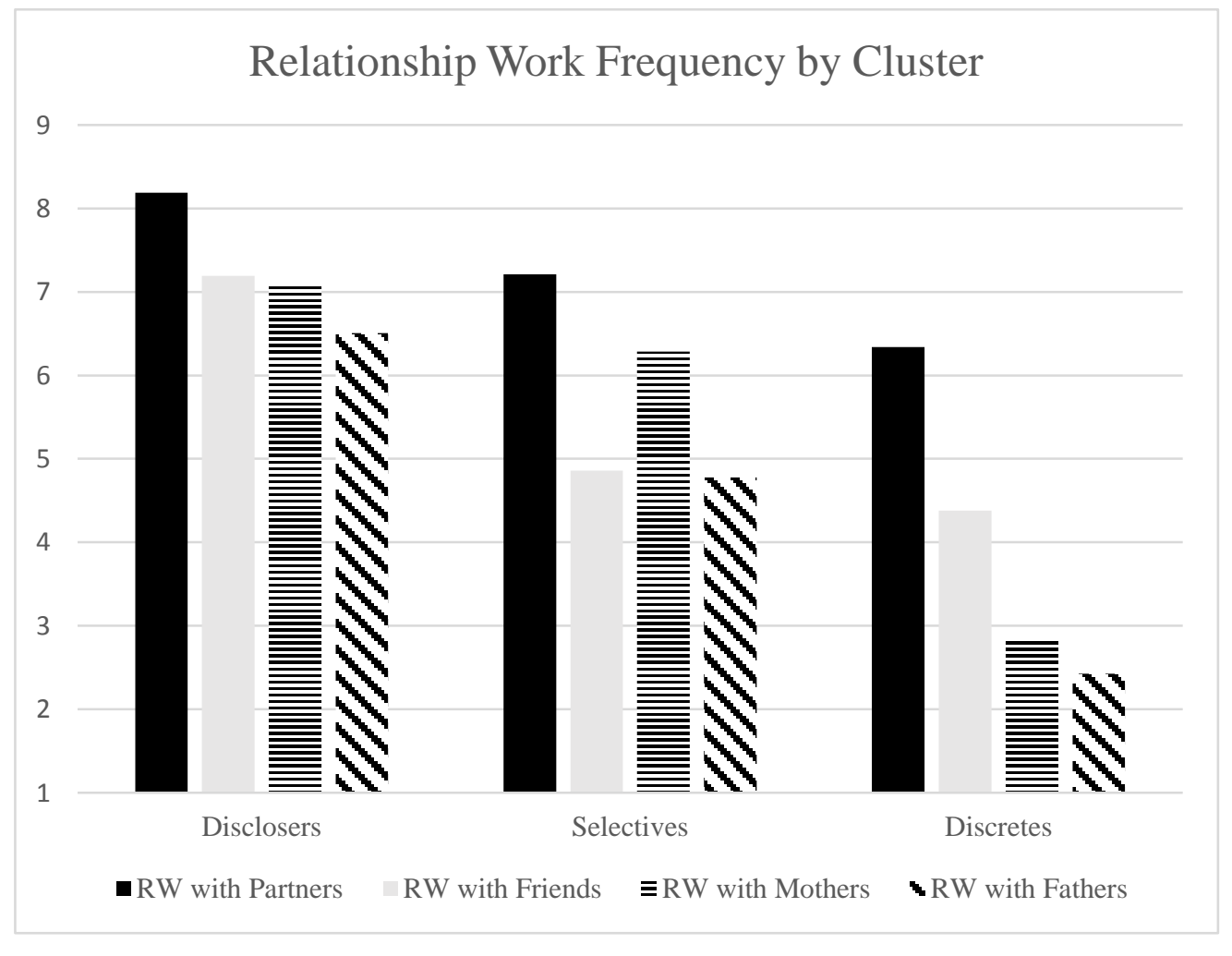

Figure 1. Relationship Work Frequency by Cluster ( $\mathrm{N}=82$ ) 
Table 2. Means (Standard Errors) of the Relationship Work (RW) Clustering Variables and the Self-Reported Relationship Correlates as a Function of Cluster Membership ( $N=82)$

\begin{tabular}{lccccc} 
Correlate & $\begin{array}{c}\text { Disclosers } \\
(n=24)\end{array}$ & $\begin{array}{c}\text { Selectives } \\
(n=35)\end{array}$ & $\begin{array}{c}\text { Discretes } \\
(n=23)\end{array}$ & $F(2,79)$ & $\eta^{2} \mathrm{p}$ \\
\hline Clustering variables & & & & & \\
$\quad$ T2 RW with partners & $8.19(.12)_{\mathrm{a}}$ & $7.21(.17)_{\mathrm{b}}$ & $6.34(.29)_{\mathrm{c}}$ & $18.63^{* * *}$ & .32 \\
T2 RW with friends & $7.19(.16)_{\mathrm{a}}$ & $4.86(.22)_{\mathrm{b}}$ & $4.37(.38)_{\mathrm{b}}$ & $31.01^{* *}$ & .44 \\
T2 RW with mothers & $7.09(0.17)_{\mathrm{a}}$ & $6.29(0.18)_{\mathrm{a}}$ & $2.85(.21)_{\mathrm{b}}$ & $122.56^{* *}$ & .76 \\
T2 RW with fathers & $6.51(.23)_{\mathrm{a}}$ & $4.78(.33)_{\mathrm{b}}$ & $2.43(.23)_{\mathrm{c}}$ & $41.46^{* *}$ & .51 \\
Correlates & & & & & \\
T2 love & $7.69(.18)_{\mathrm{a}}$ & $7.73(.12)_{\mathrm{a}}$ & $7.31(.24)_{\mathrm{a}}$ & 1.58 & .04 \\
T2 conflict & $3.07(.21)_{\mathrm{a}}$ & $3.34(.21)_{\mathrm{a}, \mathrm{b}}$ & $3.81(.26)_{\mathrm{b}}$ & $2.39^{\dagger}$ & .06 \\
\hline
\end{tabular}

Note. Means with different subscripts are significantly different from one another as tested with a Tukey's post hoc comparison.

$\dagger p<.10 .{ }^{* *} p<.01$.

\section{Are RW Behaviors Concurrently Linked With Love and Conflict?}

To examine the potential links between RW behaviors and romantic love and conflict both concurrently and over time, a series of path models was fit using Mplus 7 . All models were fully saturated (Cook \& Kenny, 2005). Figure 2 shows a model examining T2 links between the four RW variables and love and conflict among the 82 romantically involved participants at T2. Love was significantly positively linked with $\mathrm{RW}$ with partners $(\beta=.50, p<.01)$, whereas it was significantly negatively linked with RW with friends $(\beta=-.30, p<.01)$ and $\mathrm{RW}$ with fathers $(\beta=-.50, p<.01)$. Next, Figure 2 reveals that conflict was significantly positively associated with RW with friends $(\beta=$ $.29, p<.01)$ and $\mathrm{RW}$ with fathers $(\beta=.24, p<.01)$, whereas conflict was marginally negatively associated with RW with partners $(\beta=-.23, p<.10)$. Neither love nor conflict was significantly linked with RW with mothers. This model accounted for $58.2 \%$ of the variance in love and $20.1 \%$ of the variance in conflict. 


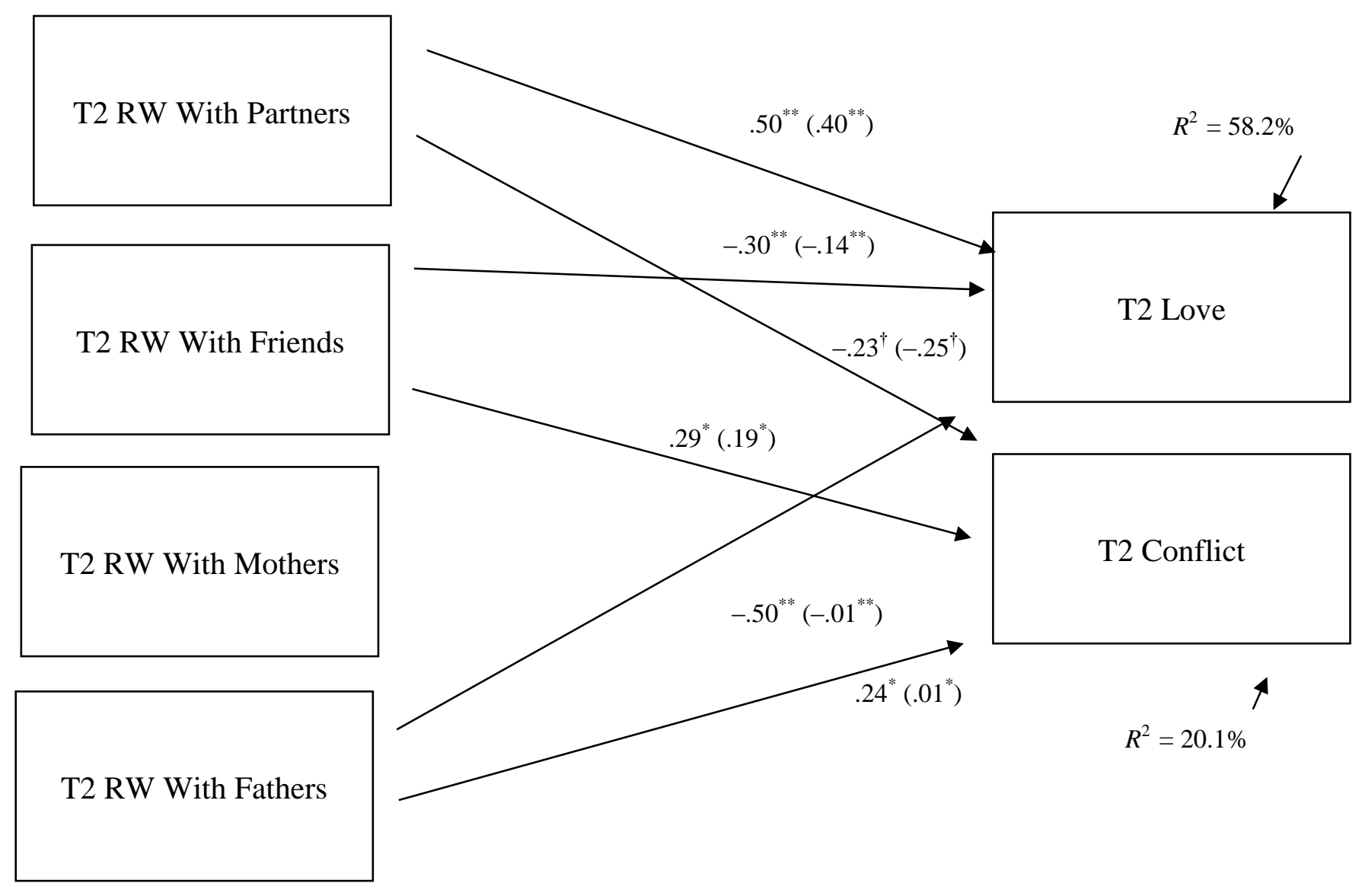

Figure 2. Fully Saturated Path Model Examining Concurrent Links Between Relationship Work (RW) With Partners, Friends, Mothers, and Fathers and Romantic Love and Conflict at Time 2 (T2; $N=82$ ). Standardized path coefficients are shown with unstandardized coefficients in parentheses. Although all pathways were examined, for ease of interpretation, only significant pathways are shown. Data were analyzed using MPlus Version 7. Full information maximum likelihood was used to handle missing data. Model fit statistics: $\chi^{2}=0.00$, comparative fit index $=1.00$, root mean square error of approximation $=0.00$; standardized root mean square residual $=0.00 .^{\dagger} p \leq .10 .^{*} p<.05 .^{* *} p<.01$. 


\section{Do Love and Conflict Predict Later Reports of RW with Parents?}

Next, we examined links between T1 love and conflict and T2 RW with mothers and fathers for those in the same relationship across both time points, controlling for autoregressive effects of love and conflict (see Figure 3). Autoregressive effects were noted such that love at T1 was significantly positively linked with love at T2 $(\beta=.70, p<.01)$. Further, conflict at T1 was linked with conflict at $\mathrm{T} 2(\beta=.60, p<.01)$. Next, we found that T1 love significantly negatively predicted T2 RW with fathers $(\beta=-.25, p<.01)$, such that greater love at T1 led to less RW with fathers 1 year later. Alternatively, Figure 3 reveals that T1 conflict marginally predicted both T2 RW with mothers $(\beta=-.23, p<.10)$ and fathers $(\beta=.23, p<.10)$, such that greater conflict at T1 was marginally linked with turning less to mothers and more to fathers 1 year later. As seen in Figure 3, no links were found between T1 love and T2 RW with mothers. This model accounted for $52.8 \%$ of the variance in T2 love, $45.5 \%$ of the variance in T2 conflict, $8.8 \%$ of the variance in T2 RW with mothers, and $12.6 \%$ of the variance in $\mathrm{T} 2 \mathrm{RW}$ with fathers.

Beyond examining the aggregate-level associations among the variables concurrently and over time, we sought to determine if differences in romantic functioning could be identified based on cluster membership (disclosers, discretes, selectives). To examine how love and conflict differed by individual patterns of RW, we conducted a series of one-way ANOVAs (see Table 2). Although there were no differences by cluster in love, discretes reported marginally greater conflict in their relationships than did disclosers (Table 2). 


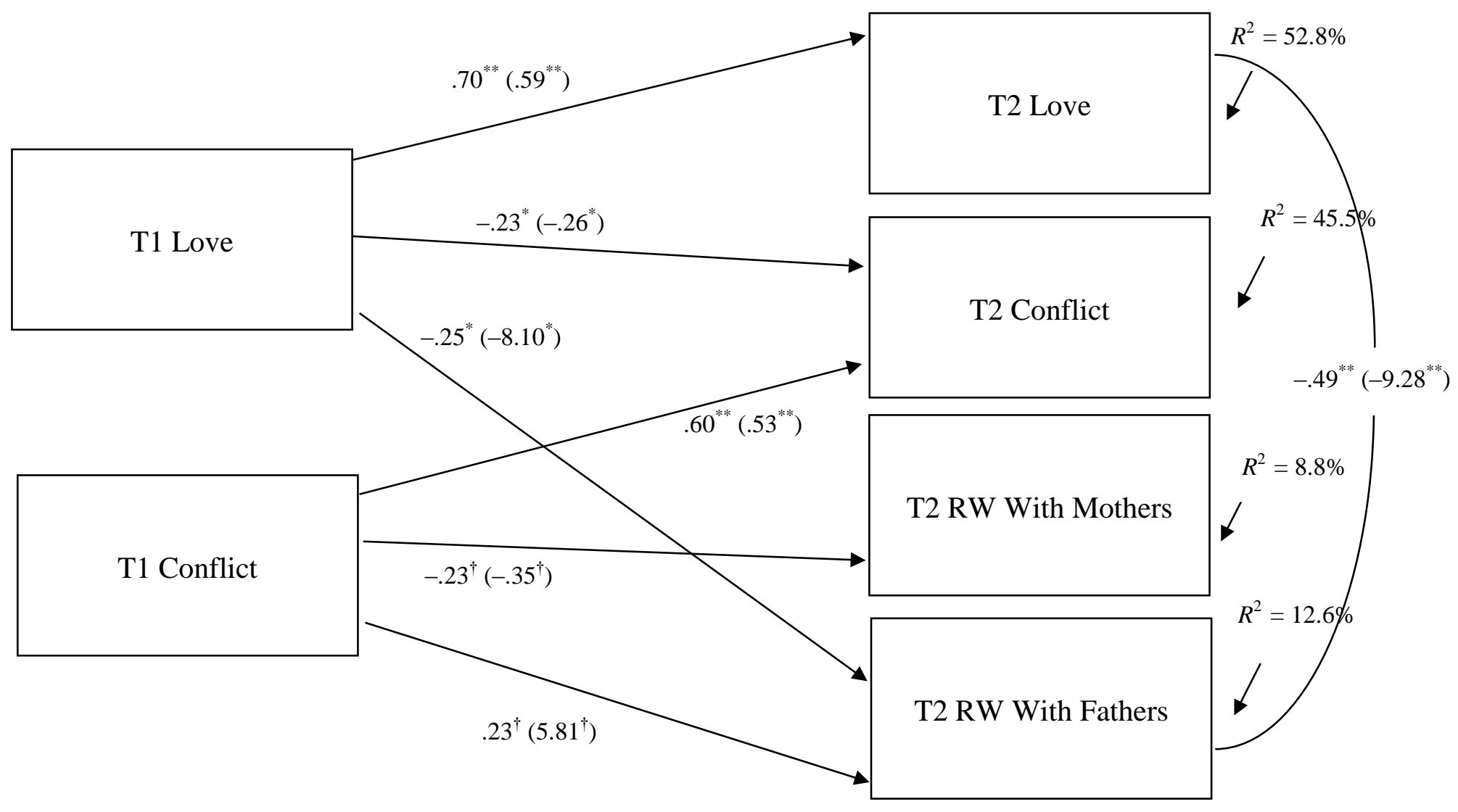

Figure 3. Fully Saturated Path Model Examining Links Between Time 1 (T1) Love and Conflict With Time 2 (T2) Love, Conflict, Relationship Work (RW) With Mothers, and RW With Fathers for Those With Same Romantic Partner From T1 to T2 ( $\mathrm{N}=56)$. Standardized path coefficients are shown with unstandardized coefficients in parentheses. For ease of interpretation, only significant pathways are shown. Data were analyzed using MPlus Version 7. Full information maximum likelihood was used to handle missing data. Model fit statistics: $\chi^{2}=0.00$, comparative fit index $=1.00$, root mean square error of approximation $=0.00$, standardized root mean square residual $=0.00{ }^{\dagger} p \leq .10 .^{*} p<.05$. ${ }^{* *} p<.01$. 


\section{Discussion}

Given the importance of social networks for romantic functioning (Fiori, Rauer, et al., 2017; Milardo, 1982), it is important to examine to whom emerging adults turn when faced with romantic challenges and the romantic correlates of these disclosures. We found emerging adults engaged in RW most frequently with partners, followed by friends and mothers, and least with fathers. Revealing considerable variability of RW patterns across emerging adults, yet somewhat distinct from our hypothesis, three unique groups emerged with key differences in disclosure patterns. Next, results suggest turning to fathers may primarily occur within the context of poorer quality romantic relationships. In contrast, turning to mothers was not linked with love or conflict either concurrently or over time. These findings add nuance to what is known of the involvement of emerging adults' social networks in their romantic lives and suggest romantic dynamics may shape parent-child communication patterns uniquely for mothers and fathers.

\section{RW Patterns Across Relationships and Individuals}

Consistent with previous literature, we found that emerging adults discuss their romantic challenges more frequently with partners than with other members of the social network (Jensen \& Rauer, 2014). Turning frequently to partners to discuss these issues has been associated with myriad positive individual and dyadic outcomes including greater romantic quality (Rodriguez et al., 2016). However, previous RW literature had not examined the central role that parents may play in emerging adults' social and romantic lives. The current study revealed that emerging adults do engage in discussions about romantic challenges with their parents, and that they do so more frequently with mothers than with fathers. In fact, mothers were turned to at an equal rate as friends, suggesting that mothers remain a key member of the social network even after children leave for college. Such a pattern may persist given the ever-increasing rate at which parents and their adult children communicate via texting and social media (Stein, Osborn, \& Greenberg, 2016). Adult children may be especially likely to engage mothers due to their likelihood of showing empathy and validation when children face trials (Aldeis \& Alfif, 2013).

Attachment theory offers a sound theoretical foundation for studying parent-child dynamics, as scholars describe a hierarchy of attachments that occurs from the cradle to the grave (Bowlby, 1982). As adolescents develop, they naturally shift their preference for emotional support from parents to friends, and finally to romantic partners (Bowlby, 1982). Regarding emerging adults' preference for engaging in RW with mothers over fathers, scholars should consider that during childhood, mothers have historically been socialized to be the child's primary attachment figure, with fathers often being more ancillary (Schmitz, 2016). In this role, mothers may be more attuned to children's cues, detect when something is wrong, and invite them to discuss the issue. Conversely, given societal messages regarding masculinity and the feminization of relationships, fathers may hold back from engaging in these discussions with their children (Schrock \& Schwalbe, 2009). Furthermore, some mothers may engage in maternal gatekeeping (i.e., maternal attitudes, beliefs and behaviors that restrict, limit, or exclude fathers from involvement with children), which has been shown to decrease father-child interactions (Stevenson et al., 2014). 
Differences within these early socialization experiences may help explain why we found such variability in emerging adults' preferences for involving others in their romantic relationships. However, these preferences appear to only be minimally linked to romantic outcomes, as those who were more likely to share their trials with others (disclosers and selectives) did not report greater love or less conflict than the discretes. Clusters may have reflected greater variability in individual personality differences (i.e., openness, conscientiousness) than romantic quality. Extraversion, for example, has been linked with increased seeking of social support as a coping strategy when experiencing personal distress (Amirkhan, Risinger, \& Swickert, 1995). Cluster differences may have also been reflective of attachment styles, given that securely attached individuals are likely to share problems with trusted others, whereas insecurely attached persons tend to avoid such disclosures (Domingue \& Mollen, 2009). Indeed, Johnson (2003) has argued that securely attached adults tend to engage in more self-disclosure about personal, social, and romantic issues in their lives because they tend to be more assertive and trust the confidant will respond supportively. Although plausible, similarities between our clusters and attachment styles remain speculative and should be validated using established measures of attachment styles in the future.

\section{RW Links to Romantic Love and Conflict: The Key Role Fathers May Play}

Our findings suggest that identifying to whom emerging adults turn when faced with romantic problems is warranted, as different confidants may yield different romantic benefits. Consistent with previous work (Helms et al., 2003; Jensen \& Rauer, 2014, 2015), greater RW with partners was concurrently linked with greater love, whereas greater RW with friends was concurrently linked with less love. However, despite its prevalence in our sample, we found no concurrent or predictive links between sharing romantic problems with mothers and romantic relationship quality. On the other hand, although RW with fathers was rare, it was concurrently linked with less love and greater conflict, suggesting that emerging adults involve their fathers in their romantic disputes when aspects of the relationships are particularly poor or challenging. Assuming that this is the case, we may have seen partners turning less to fathers in the current study because overall this sample reported high love and low conflict (see Table 1). Supporting such a conclusion are our findings that when partners reported feeling more love at T1, they reported involving fathers less in their romantic challenges at $\mathrm{T} 2$.

Gender socialization patterns may contribute to these observed patterns of RW. Whereas females are often socialized to engage in supportive discussions with one another and offer empathy and validation, males are socialized to assertively solve problems (Hook, Gerstein, Detterich, \& Gridley, 2003). Emerging adults looking for validation may avoid speaking to fathers who may be more likely to immediately provide a solution. Such a conclusion is consistent with work suggesting there are differences in the type of support men and women tend to provide. Whereas men are more socialized to provide instrumental support, women are more likely to provide emotional support (Cutrona, Shaffer, Wesner, \& Gardner, 2007). Perhaps fathers are turned to by their adult children when the romantic circumstance necessitates tangible resources (i.e., money, physical labor, transportation needs) rather than emotional challenges.

Although emerging adults may not engage their fathers in as much RW, doing so may be important for the fathers who play the role of confidant. Providing support to others has been found to be 
helpful to both physical and emotional health (Brown, Nesse, Vinokur, \& Smith, 2003; Monin, Xu, Mitchell, Buurman, \& Riffin, 2017), and men may benefit in particular from providing sensitive support in times of need (Jensen, Rauer, \& Volling, 2013). Thus, fathers' involvement in support provision to their adult children may offer a rewarding contribution to both their children's lives and their own. Therefore, if emerging adults turn to their fathers at a time of romantic turmoil, the best possible outcomes for all parties involved may occur when fathers sensitively respond to the needs of their children in such circumstances, rather than automatically seeking to come up with a solution. Although exploratory in nature, our findings certainly suggest that fathers' role and involvement should be further explored when examining emerging adult romantic relationships.

\section{Clinical Implications}

The findings of the current study may carry important implications for practitioners; though, given the limitations of our sample caution should be used when applying our findings to same-sex couples and those who are not Caucasian. Although marriage and family therapists advocate for the inclusion of family members (in addition to the identified patient) in therapy (Nichols, 2013), they do not typically involve friends or other members of the social network in clinical services (Patterson, Williams, Edwards, Chamow \& Grauf-Grounds, 2009). Given the especially critical role of the social network in shaping romantic dynamics in emerging adulthood, clinicians may benefit from including friends in the treatment process. Indeed, Hogerbrugge, Komter, and Scheepers (2012) reported that social relationships surrounding couples are key factors potentially related to the decision to dissolve or continue long-term romantic relationships. Jensen and Rauer (2015) also noted that when emerging adult women frequently disclose their romantic problems to friends they are at an increased likelihood of breaking up. Thus, either directly involving members of the social network in therapy, or at a minimum thoroughly assessing for the influence of the social network on romantic affairs seems warranted.

Next, our findings suggest that when working with emerging adult couples, clinicians should be more aware of the influence of parents on the romantic relationship. Previously cited research has shown that mothers especially tend to offer life advice and counsel to their romantically involved emerging adult children (Aldeis \& Alfif, 2013) and this information is likely underutilized by most counselors. Clinicians may also want to consider focusing on parental approval of partners, joint activities with parents, or communication between partners and parents regarding the romantic relationship (Guerrero, Andersen, \& Afifi, 2017). Furthermore, clinicians may be aided by assessing when parents are apprised of their children's romantic challenges (e.g., communication issues, infidelity) and when mothers versus fathers are informed. Assessing for father involvement may provide an indication of the severity of the problem, given that fathers tend to be turned to when problems are more serious. However, clinicians should exercise caution when encouraging parents to become involved in young adult children's lives, as Reed, Duncan, Lucier-Greer, Fixelle, and Ferraro (2016) found that autonomy-supportive parenting, as opposed to helicopter parenting, predicted greater well-being among college-age children. Clinicians should also consider assessing attachment style (a common clinical practice) and examining potential links between attachment and RW with partners, friends, and parents. For example, an emerging adult who demonstrates avoidant attachment tendencies may be less inclined to engage in RW with partner or others. Such 
information may be useful in fostering opportunities for clients to develop emotionally fulfilling relationships (Guerrero et al., 2017; Wei et al., 2005).

Furthermore, clinical services may be enhanced by processing with partners to whom they should disclose their romantic trials. This negotiation should take place at the couple level as therapists process with the couple which confidants would be classified as friends of the relationship versus those who are more likely to act as supporters of only one partner. Those who simply support the position of one partner may inadvertently harm the relationship by validating one partner's position, leading to further entrenchment of the partner's opinion, rather than facilitating negotiation and compromise. Conversely, a friend of the relationship may offer advice or support that will enhance the likelihood of the couple working through the issue (i.e., "I know she has always been a good partner to you, so this seems like an exception, not the norm"). This processing between couple and clinician regarding who should be apprised of problems may be especially important in the case of serious violations of trust such as infidelity.

\section{Considerations and Conclusions}

Although our multiassessment approach was the first to examine RW with parents, certain limitations should be considered. Self-report data must always be treated with caution due to the possibility of recall error, reporter bias, and other limitations. The exploratory nature of the study also yielded a smaller than expected sample size and we may have been unable to detect gender differences due to the modest number of males in our study, an issue common to work on socioemotional dynamics in this population (Fiori, Buthmann, \& Denckla, 2017). Therefore, caution should be exercised when extrapolating our results to young adult males. Males were underrepresented suggesting that results of the study may be more relevant for young adult females. Furthermore, the heterosexual nature of the sample and its overwhelmingly Caucasian makeup limit generalizability, as same-sex partners tend to rely more heavily on friendships than on family for social support (Kurdek, 2004). Moreover, as African Americans are more likely than Caucasians to offer relational support to extended family members (Taylor, Chatters, Woodward, \& Brown, 2013), and Hispanics tend to have closer, more supportive family systems than do Caucasians (McEachern \& Kenny, 2002), RW with friends and parents may be more normative for these emerging adults. It is also important to recognize that not all emerging adults go to college. Hence, the results may not be generalizable to a more representative sample of young adults. Moreover, the results may have been influenced by participants' history of relationship experiences as well as both partners' and friends' subscription to traditional gender roles.

Additionally, although the RW measure (Helms et al., 2003) did cover a variety of potential romantic problems (e.g., decision-making, finances, leisure time), the current study did not specifically consider which topics were more likely to be discussed with partners, friends, or parents. Topic choice may have significantly impacted to whom emerging adults disclosed. For example, Carlson (2014) contended that emerging adults are much more likely to speak with parents about financial challenges than romantic and social concerns. Consequently, future researchers should consider conducting a qualitative study with similar research questions, which may enhance understanding regarding emerging adult romantic dynamics. Further, given that RW was not captured at T1, our ability to comment change in RW over time is limited. Additionally, although the five RW questions 
captured a wide range of topics in relationships, relations with the partner's family and financial concerns may not be discussed among some dating couples very often, which is a limitation of our measure. Finally, accounting for the mode of communication (i.e., face to face, texting, phone call) may provide greater insight regarding these conversations, such as potential depth of feedback provided, possibility of physical contact (e.g., a parent hugging a child during/after engaging in a RW conversation), or availability of confidant (e.g., fathers are less likely to text, which may account somewhat for them being turned to less frequently than mothers and friends; Crosswhite, Rice, \& Asay, 2014).

Lastly, despite literature suggesting that overall better parent-child communication is linked with more disclosure (Arnold et al., 2013), the current study did not assess for parent-child relationship quality or communication dynamics. Given our modest sample size, which limited the number of variables we could examine, and our desire to extend previous literature, we were interested in examining how romantic partner dynamics were linked with involving parents in romantic concerns. Future work should account for parent-child relationship quality and communication when seeking to understand how and why romantic partners involve their parents. Future studies should also examine the role of extended family, such as the impact of engaging in RW with grandparents or siblings, as well as examining how RW is engaged in on social media (Ruiz \& Stadtlander, 2015).

In conclusion, emerging adults today find themselves in an unprecedented position. Though it is widely believed that emerging adults should focus on separating from parents and forming healthy romantic relationships (Erikson, 1968; Rauer et al., 2013), today's parents are more involved in the romantic affairs of their emerging adult children and this involvement merits further investigation (Reed et al., 2016). Thus, researchers should continue heeding the call made by Bradbury and colleagues (2000) nearly 2 decades ago; namely, to give greater consideration to the routine interactions couples have with their social network, including friends and parents. When emerging adults decide to involve others in their romantic challenges, they may also be impacting their own romantic relationships in unanticipated ways that require additional consideration. Accordingly, those who work with emerging adults should use caution when recommending that they turn toward friends or parents to work on romantic challenges, especially in lieu of turning to partners. There may be some advantage in also being selective about which parent to use as a confidant. Given the findings of the current study, it may be wise to involve mothers in one's run-of-the-mill romantic disputes and turn to fathers when problems become more serious. Sharing romantic trials with others is a normative part of any relationship. Yet, the ways in which problems are shared, as well as with whom they are shared, continue to be influential features of emerging adult romantic dynamics and deserve additional attention.

\section{References}

Aldeis, D., \& Alfif, T. D. (2013). College students' willingness to reveal risky behaviors: The influence of relationship and message type. Journal of Family Communication, 13, 92-113. doi:10.1080/15267431.2013.768246

Amirkhan, J., Risinger, R., \& Swickert, R. (1995). Extraversion: A "hidden" personality factor in coping? Journal of Personality, 63, 189-212. doi:10.1111/j.1467-6494.1995.tb00807.x 
Arnett, J. J., Zukauskiene, R., \& Sugimura, K. (2014). The new life stage of emerging adulthood at ages 18-29 years: Implications for mental health. Lancet Psychiatry, 1, 569-576.

Arnold, A., O'Neal, C., \& Futris, T. (2013). Parent-daughter communications and emerging adults' beliefs about mate selection. Journal of Adult Development, 20, 16-26. doi:10.1007/s10804012-9152-4

Bentler, P. M. (1995). EQS structural equations program manual [Computer software manual]. Encino, CA: Multivariate Software.

Bowlby, J. (1982). Attachment and loss. Vol. 1: Attachment (2nd Ed.). New York, NY: Basic Books.

Bradbury, T., Fincham, F., \& Beach, S. (2000). Research on the nature and determinants of marital satisfaction: A decade in review. Journal of Marriage and the Family, 62, 964-980.

Braiker, H., \& Kelley, H. H. (1979). Conflict in the development of close relationships. In R. L. Burgess \& T. L. Huston (Eds.), Social exchange in developing relationships (pp. 135-167). New York, NY: Academic Press.

Brown, S. L., Nesse, R. M., Vinokur, A. D., \& Smith, D. M. (2003). Providing social support may be more beneficial than receiving it: Results from a prospective study of mortality. Psychological Science, 14, 320-327. doi:10.1111/1467-9280.14461.

Carlson, C. (2014). Seeking self-sufficiency: Why emerging adult college students receive and implement parental advice. Emerging Adulthood, 2, 257-269. doi:10.1177/2167696814551785

Cook, W., \& Kenny, D. (2005). The actor-partner interdependence model: A model of bidirectional effects in developmental studies. International Journal of Behavioral Development, 29, 101109. doi:10.1080/01650250444000405

Coomes, M., \& DeBard, R. (2004). A generational approach to understanding students. In M. D. Coomes \& R. DeBard (Eds.), Serving the millennial generation, new directions for student services (pp. 5-66). San Francisco, CA: Jossey-Bass.

Crosswhite, J., Rice, R., \& Asay, S. (2014). Texting among United States young adults: An exploratory study on texting and its use within families. The Social Science Journal, 51, 7078.

Cutrona, C., Shaffer, P., Wesner, K., \& Gardner, K. (2007). Optimally matching support and perceived spousal sensitivity, Journal of Family Psychology, 21, 754-758. doi:10.1037/08933200.21.4.754

Domingue, R., \& Mollen, D. (2009). Attachment and conflict communication in adult romantic relationships. Journal of Social and Personal Relationships, 26, 678-696. doi:10.1177/0265407509347932

Erikson, E. H. (1968). Identity: Youth and crisis. New York, NY: Norton.

Etcheyerry, P. E., \& Agnew, C. R. (2004). Subjective norms and the prediction of romantic relationship state and fate. Personal Relationships, 11, 409-428. doi:10.1111/j.1475f6811.2004.00090.x 
Fiori, K., Buthmann, J., \& Denckla, C. (2017). Crying and attachment style: The role of romantic relationships. Journal of Social, Behavioral, and Health Sciences, 11, 133-146. doi:10.5590/JSBHS.2017.11.1.09

Fiori, K., Rauer, A., Birditt, K., Brown, E., Jager, J., \& Orbuch, T. (2017). Social network typologies of Black and White couples in midlife. Journal of Marriage and Family, 79, 571-589.

Fisher, C., \& Miller-Day, M. (2006). Communication over the lifespan: The mother-adult daughter relationship. In K. Floyd \& M. T. Morman (Eds.), Widening the family circle: New research on family communication (pp. 3-19). Thousand Oaks, CA: Sage.

Gentzler, A., Oberhauser, A., Westerman, D., \& Nadorf, D. (2011). College students' use of electronic communication with parents: Links to loneliness, attachment, and relationship quality. Cyberpsychology, Behavior, and Social Networking, 14, 71-74.

Guerrero, L. K., Andersen, P. A., \& Afifi, W. A. (2017). Close encounters: Communication in relationships. Thousand Oaks, CA: Sage Publications.

Hair, J., \& Black, W. (1998). Cluster analysis. In J. Hair, R. Anderson, R. Tatham, \& W. Black (Eds). Multivariate analysis (pp. 147-205). Upper Saddle River, NJ: Prentice International.

Helms, H., Crouter, C., \& McHale, S. (2003). Marital quality and spouses' marriage work with close friends and each other. Journal of Marriage and Family, 65, 963-977. doi:10.1111/j.17413737.2003.00963.x.

Henry, D. B., Tolan, P. H., \& Gorman-Smith, D. (2005). Cluster analysis in family psychology research. Journal of Family Psychology, 19, 121-132.

Hogerbrugge, M., Komter, A., \& Scheepers, P. (2012). Dissolving long-term romantic relationships: Assessing the role of the social context. Journal of Social and Personal Relationships, 30, 320-342. doi:10.1177/0265407512462167

Hook, M., Gerstein, L., Detterich, L., \& Gridley, B. (2003). How close are we? Measuring intimacy and examining gender differences. Journal of Counseling and Development, 81, 462-472. doi:10.1002/j.1556-6678.2003.tb00273.x.

Hu, L. T., \& Bentler, P. M. (1999). Cutoff criteria for fit indexes in covariance structure analysis: Conventional criteria versus new alternatives. Structural Equation Modeling, 6, 1-55. doi:10.1080/10705519909540118.

Huston, T. L. (2000). The social ecology of marriage and other intimate unions. Journal of Marriage and Family, 62, 298-320. doi:10.1111/j.1741-3737.2000.00298.x

Jensen, J., \& Rauer, A. (2014). Turning inward versus outward: Relationship work in young adults and romantic functioning. Personal Relationships, 21, 451-467. doi:10.1111/pere.12042

Jensen, J., \& Rauer, A. J. (2015). Young adults' females relationship work and it links to romantic functioning and stability over time. Journal of Social and Personal Relationships, 5, 1-22. doi:10.1177/0265407515588221

Jensen, J., Rauer, A., \& Volling, B. (2013). A dyadic view of support in marriage: The critical role of men's support provision. Sex Roles, 68, 427-438. doi:10.1007/s11199-012-0256-x 
Johnson, S. M. (2003). Attachment theory: A guide for couple therapy. In S. M. Johnson \& V. E. Whiffen (Eds.), Attachment processes in couple and family therapy (pp. 103-123). New York, NY: Guildford Press.

Kanter, M., Afifi, T., \& Robbins, S. (2012). The impact of parents "friending" their young adult child on Facebook on perceptions of parental invasions and parent-child relationship quality. Journal of Communication, 62, 900-917. doi:10.1111/j.1460-466.2012.01669.x

Kurdek, L. (2004). Are gay and lesbian cohabiting couples really different from heterosexual married couples? Journal of Marriage and the Family, 66, 880-900.

Lavner, J., Karney, B., \& Bradbury, T. (2016). Does couples' communication predict marital satisfaction, or does marital satisfaction predict communication? Journal of Marriage and Family, 78, 680-694. doi:10.1111/jomf.12301

Markiewicz, D., Lawford, H., Doyle, A., \& Haggart, N. (2006). Developmental differences in adolescents' and young adults' use of mothers, fathers, best friends, and romantic partners to fulfill attachment needs. Journal of Youth and Adolescence, 35, 127-140. doi:10.1007/s10964005-90145

McEachern, A., \& Kenny, M. (2002). A comparison of family environment characteristics among White (non-Hispanic), Hispanic, and African Caribbean groups. Journal of Multicultural Counseling and Development, 30, 40-58.

Milardo, R. (1982). Friendship networks in developing relationships: Converging and diverging social environments. Social Psychology Quarterly, 45, 162-172.

Milligan, G. W., \& Cooper, M. C. (1985). An examination of procedures for determining the number of clusters in a data set. Psychometrika, 50, 159-179.

Milligan, G. W., \& Cooper, M. C. (1988). A study of standardization of variables in cluster analysis. Journal of Classification, 5, 181-204.

Monin, J. K., Xu, A., Mitchell, H. R., Buurman, F., \& Riffin, C. (2017). Recalling support provision decreases distress and anger in response to partner suffering. Aging \& Mental Health. Advance online publication.

Mooi, E., \& Sarstedt, M. (2010). A concise guide to market research. Berlin, Germany: Springer.

Morgan, E. M., Thorne, A., \& Zurbriggen, E. I. (2010). A longitudinal study of conversations with parents about sex and dating during college. Developmental Psychology, 46, 139-150. doi:10.1037/a0016931

Nichols, M. (2013). The essentials of family therapy (6th ed.). Boston, MA: Allyn \& Bacon.

Patterson, J., Williams, L., Edwards, T. M., Chamow, L., \& Grauf-Grounds, C. (2009). Essential skills in family therapy: From the first interview to termination. New York, NY: Guilford Press.

Pederson, D. (2017). Parental autonomy support and college student academic outcomes. Journal of Child and Family Studies, 26, 2589-2601. doi:10.1007/s10826-017-0750-4 
Pizzolato, J., \& Hicklen, S. (2011). Parent involvement: Investigating the parent-child relationship in Millennial college students. Journal of College Student Development, 52, 671-686. doi:10.1353/csd.2011.0081

Proulx, C. M., Helms, H. M., \& Payne, C. C. (2004). Wives' domain specific "marriage work" with friends and spouses: Links to marital quality. Family Relations, 53, 393-404. doi:10.1111/j.0197-664.2004.00046.x

Ratelle, C., Simard, K., \& Guay, F. (2013). University students' subjective well-being: The role of autonomy support from parents, friends, and the romantic partner. Journal of Happiness Studies, 14, 893-910. doi:10.1007/s10902-012-9360-4

Rauer, A., Pettit, G., Lansford, J., Bates, J., \& Dodge, K. (2013). Romantic relationship patterns in young adulthood and their developmental antecedents. Developmental Psychology, 49, 21592171. doi:10.1037/a0031845

Reed, K., Duncan, J. M., Lucier-Greer, M., Fixelle, C., \& Ferraro, A. J. (2016). Helicopter parenting and emerging adult self-efficacy: Implications for mental and physical health. Journal of Child and Family Studies, 25, 3136-3149. doi:10.1007/s10826-016-0466-x

Rodriguez, Y., Helms, H., Supple, A., \& Hengstebeck, N. (2016). Mexican immigrant wives' acculturative stress and spouses' marital quality: The role of wives' marriage work with husbands and friends. Journal of Family Issues, 37, 1678-1702. doi:10.1177/0192513X14561519

Ruiz, S., \& Stadtlander, L. (2015). Social media as support for partners of veterans with posttraumatic stress disorder. Journal of Social, Behavioral, and Health Sciences, 9, 1-18. doi:10.5590/JSBHS.2015.09.1.01

Schiffrin, H. H., Liss, M., Miles-McLean, H., Geary, K. A., Erchull, M. J., \& Tashner, T. (2014). Helping or hovering? The effects of helicopter parenting on college students' well-being. Journal of Child and Family Studies, 23, 548-557.

Schmitz, R. M. (2016). Constructing men as fathers: A content analysis of formulations of fatherhood in parenting magazines. The Journal of Men's Studies, 1, 1-21. doi:1060826515624381

Schrock, D., \& Schwalbe, M. (2009). Men, masculinity, and manhood acts. Annual Review of Sociology, 35, 277-295. doi:http://www.jstor.org/stable/27800079

Smetana, J., Metzger, A., Gettmen, D., \& Campione-Barr, N. (2006). Disclosure and secrecy in adolescent-parent relationships. Child Development, 77, 201-217. doi:10.1111/j.14678624.2006.00865.x

Sprecher, S., \& Felmlee, D. (1992). The influence of parents and friends on the quality and stability of romantic relationships: A three-wave longitudinal investigation. Journal of Marriage and the Family, 54, 888-900. doi:10.2307/353170

Steiger, J., \& Fouladi, R. (2009). R2 user's guide version 1.1. Retrieved from http://statpower.net/Content/R2/R2\%20Manual.pdf 
Stein, C., Osborn, L., \& Greenberg, S. (2016). Understanding young adults' reports of contact with their parents in a digital world: Psychological and familial relationship factors. Journal of Child and Family Studies, 25, 1802-1814. doi:10.1007/s10826-016-0366-0

Stevenson, M. M., Fabricius, W. V., Cookston, J. T., Parke, R. D., Coltrane, S., Braver, S. L., \& Saenz, D. S. (2014). Marital problems, maternal gatekeeping attitudes, and father-child relationships in adolescence. Developmental Psychology, 50, 1208-1218.

Taylor, R., Chatters, L., Woodward, A., \& Brown, E. (2013). Racial and ethnic differences in extended family, friendship, fictive kin, and congregational informal support networks. Family Relations, 62, 609-624. doi:10.1111/fare.12030

Ward, J. H. (1963). Hierarchical grouping to optimize an objective function. Journal of the American Statistical Association, 58, 236-244.

Wei, M., Russell, D., Zakalik, R. (2005). Adult attachment, social self-efficacy, self-disclosure, loneliness, and subsequent depression for freshman college students: A longitudinal study. Journal of Counseling Psychology, 52, 602-614.

The Journal of Social, Behavioral, and Health Sciences is an open-access, peer-reviewed, online interdisciplinary journal focusing on research findings that address contemporary national and international issues. Its objectives are to (a) encourage dialogue between scholars and practitioners in the social, behavioral, and health sciences that fosters the integration of research with practice; (b) promote innovative models of interdisciplinary collaboration among the social, behavioral, and health sciences that address complex social problems; and (c) inform the relationship between practice and research in the social, behavioral, and health sciences.

Walden University Publishing: http://www.publishing.waldenu.edu 